\title{
Sleep quality according to the Pittsburgh Sleep Quality Index in over 7000 pregnant women in Poland
}

\author{
Magdalena Smyka ${ }^{1}$ Katarzyna Kosińska-Kaczyńska ${ }^{2}$ - Nicole Sochacki-Wójcicka $\cdot$ Magdalena Zgliczyńska ${ }^{2}$. \\ Mirosław Wielgoś ${ }^{1}$
}

Received: 17 December 2020 / Accepted: 16 April 2021 / Published online: 4 May 2021

(c) The Author(s) 2021

\begin{abstract}
The aim was to assess sleep quality in pregnant women, characterize sleep patterns in each trimester and to establish independent risk factors of poor sleep quality during gestation. A cross-sectional survey was conducted. The questionnaire included questions regarding sociodemographic data, information on the current pregnancy, sleep patterns and Pittsburgh Sleep Quality Index. 7202 respondents fulfilled the survey completely and only those were included. A total of $95.1 \%$ of the respondents in the first trimester, $93 \%$ in the second trimester and $94.8 \%$ in the third trimester had poor sleep quality. Significantly more women with poor sleep quality assessed their socioeconomic status as bad or sufficient (15.7 vs $8.8 \%$; $p<0.001$ ), stress level as higher (mean 4.7 points vs 3.9 points; $p<0.001$ ), had lower relationship rating (mean 8.8 points vs 9.3 points; $p<0.001$ ) or suffered from depression and anxiety disorders. Logistic regression revealed pregnancy ailments to be the strongest independent risk factors of poor sleep quality during gestation. Sleep disorders are common among pregnant women in Poland and increase significantly as the pregnancy progresses. Developing and introducing a simple and easily available screening tool to assess sleep quality in common practice might improve the quality of the health care of pregnant women.
\end{abstract}

Keywords Pregnancy $\cdot$ Sleep · Pittsburgh Sleep Quality Index

\section{Introduction}

Sleep is an essential biological function in humans [1]. Pregnancy seems to be one of the periods in life with the highest likelihood of developing sleep disorders, as they are widespread in pregnant women. Hormonal and psychological changes, which occur during pregnancy, are related to the deterioration of sleep quality [2]. Moreover, physical body changes during pregnancy lead to the deterioration of both sleep quality and sleep duration. Nighttime awakening, frequent urination, uncomfortable body position or daytime naps affect nighttime rest. According to the literature

Katarzyna Kosińska-Kaczyńska

katarzyna.kosinska-kaczynska@cmkp.edu.pl

1 1st Department of Obstetrics and Gynecology, Medical University of Warsaw, Starynkiewicza Square 1/3, 02-015 Warsaw, Poland

2 2nd Department of Obstetrics and Gynecology, The Center of Postgraduate Medical Education, Cegłowska St. 80, 01-809 Warsaw, Poland sociodemographic factors, such as the economic or marital status, type of living area and smoking also exert a significant impact on sleeping patterns [2,3]. Available studies emphasize that sleep disorders not only disturb nighttime rest, but also make pregnant women more likely to suffer from depression or anxiety [4-6]. The rate of sleep problems increases significantly as the pregnancy progresses and poor sleep quality in the third trimester and perinatal period seems to be crucial for a woman's health and the care of a newborn $[3,7]$.

Previously published studies used the Pittsburgh Sleep Quality Index (PSQI) to assess the sleep quality of expectant mothers [8-10]. The original study of the PSQI validation indicated that a cut-off score of above 5 may be used to identify good and poor sleepers and it has been used to differentiate between groups of expectant mothers [11].

The aim of the study was to asses sleep quality in pregnant women according to the PSQI, characterize sleep patterns in each trimester of pregnancy and to establish independent risk factors of poor sleep quality during gestation. 


\section{Materials and methods}

We conducted a cross-sectional survey. A self-composed questionnaire was distributed via internet between February and March 2018. It was dedicated to pregnant Polishspeaking women, regardless of inhabitancy and was distributed by web pages and Facebook groups, which were designed for pregnant women. Web pages written in Polish language provided general medical and social information on pregnancy and were available without any limits. The questionnaire was administered by Google Forms (Google LLC, Mountain View, California, US). Link to the survey was presented on web pages providing general information on pregnancy and pregnancy ailments Facebook groups were accessible for women declaring being pregnant without any special requirements. Neither Facebook groups nor web pages were advertised at the time of the survey. On websites and Facebook group, a short information on sleep problems in pregnancy and its importance was presented with an invitation to complete the survey.

Women aged over 18 years old and pregnant at the time of the survey were included in the study. Only questionnaires which were filled in completely were considered in the analysis. Women declaring having sleep problems before the current pregnancy were also included in the analysis. Women in multiple pregnancies were excluded.

The first part of the questionnaire included questions regarding sociodemographic data, information on the current pregnancy, including pregnancy ailments, and ones that characterized sleep patterns like sleep duration, occurrence of daytime naps or factors deteriorating sleep quality. Gestational age was calculated on the basis of the first day of the last menstrual period or the transfer day in assisted reproduction technique procedures reported by the respondents. In case of differences in gestational age exceeding 5 days after the verification of the crown-rump length (CRL) measured on the first-trimester scan, gestational age calculated on the basis of CRL was used in further analyses.

The second part of the questionnaire contained PSQI, which is commonly used to measure sleep quality and patterns of sleep in adults [12-26]. The PSQI differentiates "poor" from "good" sleep by measuring seven components: subjective sleep quality, sleep latency, sleep duration, habitual sleep efficiency, sleep disturbances, use of sleep medication, and daytime dysfunction over the past four weeks. The PSQI includes questions concerning usual time in bed, number of minutes needed to fall asleep, usual time of getting up, hours of sleep per night, and factors which deteriorated sleep quality over the past four weeks. Medication use, daytime alertness, snoring and pauses between breaths are also assessed. The answers are given using a 4-grade scale, which describes the frequency of incidents: 0-the were no incidents over the past 4 weeks, 1 -less than once a week, 2-once or twice a week, 3-three times a week or more. The results are evaluated regarding the above seven components, assessed from 0 to 21 points in total. Results higher than 5 points indicate low sleep quality and differentiates patients into with "poor" and "good" sleep [11, 14, 16-18]. The PSQI questionnaire is characterized by high in-ternal consistency, with Cronbach's alpha index of 0.83 [14]. Its high reliability and validity were observed in numerous populations of pregnant women around the world: Hungarian, Italian, Brazilian, Peruvian, Serbian, Persian, PacificNorthwest or Georgian (USA) [18-24]. The Polish version of the PSQI was validated and previously used by other researchers [25].

Life stress level and satisfaction with the current relationship were assessed with a visual numerical scale from 0 to 10 . Women over the age of 18 , currently pregnant and speaking Polish were included in the study. No specific criteria other than singleton pregnancy at the time of the survey were used for recruitment for the study. The survey was voluntary and anonymous-no questions regarding personal data that would enable the identification of participants were included and only the authors of the study had access to the collected information. Access to the questionnaire was granted after login only once. The respondents were asked to describe their sleep experience over the past four weeks. Only fully completed questionnaires were comprised in the analysis. The answers were double-checked by the researchers and there were no identical records.

Data were reported as absolute numbers and percentages or means and standard deviations. Statistical analyses were performed using Statistica version 13.3. The Mann-Whitney test or Fisher exact tests were used to compare the analyzed variables. All tests were two tailed and $p<0.05$ was considered significant. Logistic regression analysis was performed to determine the independent risk factors of sleep problems during pregnancy.

The study protocol obtained the approval of the Ethics Committee of the Medical University of Warsaw (no. 124/2018). The committee retreated from the obligation of having a written or verbal consent to participate in the study. Completing the questionnaire was deemed tantamount to giving consent.

A power analysis was performed to assess the minimal number of respondents. For the $90 \%$ power, with a value of the zero hypothesis $90 \%$ (as basing on the available published Polish data, we assumed that $90 \%$ of pregnant women declare having any sleep problems), 1000 women should be included in the study ( $\mathrm{G}^{*}$ Power 3.1.9.4, Franz Faul, Christian-Albrecht University, Kiel, Germany). 
The results of the study concerning the subjective assessment of sleep quality conducted in the same study population were presented in previously published paper [26].

\section{Results}

7855 pregnant women participated in the survey. The questionnaires were fully completed by 7207 respondents and only those were included.

$791(11 \%)$ respondents were in the first trimester, 2580 $(35.8 \%)$ in the second trimester and $3836(46.8 \%)$ in the third trimester of pregnancy at the time of the survey. Baseline characteristics of the study group are presented in Table 1.

$12.9 \%$ of women declared that they had slept over $9 \mathrm{~h}$ per day, $75.3 \%$ - from 7 to $8 \mathrm{~h}$ per day, and $11.9 \%$ - less than $6 \mathrm{~h}$ per day prior to the current pregnancy. Significant changes in sleep duration during pregnancy were observed. The number of women sleeping over $9 \mathrm{~h}$ per day and less than $6 \mathrm{~h}$ per day increased during gestation $(16.5 \%, p<0.001,39.5 \%$, $p<0.001)$, while fewer respondents reported sleeping from 7 to 8 h per day $(44.1 \%, p<0.001)$.

Significant differences were observed as regards sleep patterns of women in all three trimesters of pregnancy.

Table 1 Characteristics of the study group and respondents with poor and good sleep according to the results of the Pittsburgh Sleep Quality Index

\begin{tabular}{|c|c|c|c|c|c|c|c|c|}
\hline & & \multicolumn{2}{|c|}{$\begin{array}{l}\text { Study group } \\
N=7207\end{array}$} & \multicolumn{2}{|c|}{$\begin{array}{l}\text { Poor sleep } \\
N=6788\end{array}$} & \multicolumn{2}{|c|}{$\begin{array}{l}\text { Good sleep } \\
N=419\end{array}$} & \multirow[b]{2}{*}{$p$} \\
\hline & & No & $\%$ & No & $\%$ & No & $\%$ & \\
\hline \multicolumn{2}{|l|}{ Age $(\text { years })^{*}$} & 28 & 3.8 & 28.09 & 3.85 & 28.24 & 3.59 & 0.4 \\
\hline \multicolumn{2}{|l|}{ Pre-pregnancy BMI $\left(\mathrm{kg} / \mathrm{m}^{2}\right)^{*}$} & 23.25 & 4.3 & 23.26 & 4.14 & 23.04 & 3.59 & 0.3 \\
\hline \multicolumn{2}{|l|}{ Primiparity } & 4954 & 68.74 & 4659 & 68.64 & 295 & 70.4 & 0.4 \\
\hline Trimester & $\begin{array}{l}1 \mathrm{st} \\
2 \mathrm{nd} \\
3 \mathrm{rd}\end{array}$ & $\begin{array}{l}791 \\
2580 \\
3836\end{array}$ & $\begin{array}{l}11 \\
35.8 \\
53.2\end{array}$ & $\begin{array}{l}752 \\
2399 \\
3637\end{array}$ & $\begin{array}{l}11.08 \\
35.34 \\
53.58\end{array}$ & $\begin{array}{l}39 \\
181 \\
199\end{array}$ & $\begin{array}{l}9.3 \\
43.2 \\
47.5\end{array}$ & $\begin{array}{l}<0.001 \\
0.001 \\
0.02\end{array}$ \\
\hline Education & $\begin{array}{l}\text { Primary } \\
\text { Vocational } \\
\text { Secondary } \\
\text { Tertiary }\end{array}$ & $\begin{array}{l}35 \\
147 \\
1491 \\
5542\end{array}$ & $\begin{array}{l}0.49 \\
2.04 \\
20.69 \\
76.9\end{array}$ & $\begin{array}{l}35 \\
139 \\
1409 \\
5213\end{array}$ & $\begin{array}{l}0.52 \\
2.05 \\
20.79 \\
76.64\end{array}$ & $\begin{array}{l}0 \\
8 \\
82 \\
329\end{array}$ & $\begin{array}{l}0 \\
1.91 \\
19.57 \\
78.52\end{array}$ & $\begin{array}{l}0.3 \\
1 \\
0.6 \\
0.3\end{array}$ \\
\hline Inhabitancy & $\begin{array}{l}\text { Village } \\
<50,000 \text { inh } \\
50,000-200,000 \text { inh } \\
>200,000 \text { inh }\end{array}$ & $\begin{array}{l}1708 \\
1426 \\
1598 \\
2475\end{array}$ & $\begin{array}{l}23.70 \\
19.79 \\
22.17 \\
34.34\end{array}$ & $\begin{array}{l}1614 \\
1336 \\
1513 \\
2325\end{array}$ & $\begin{array}{l}23.81 \\
19.71 \\
22.32 \\
65.84\end{array}$ & $\begin{array}{l}94 \\
90 \\
85 \\
150\end{array}$ & $\begin{array}{l}22.43 \\
21.48 \\
20.29 \\
35.8\end{array}$ & $\begin{array}{l}0.6 \\
0.4 \\
0.4 \\
0.5\end{array}$ \\
\hline Employment & $\begin{array}{l}\text { Unemployed } \\
\text { Physical work } \\
\text { Mental work }\end{array}$ & $\begin{array}{l}1246 \\
1319 \\
4642\end{array}$ & $\begin{array}{l}17.30 \\
18.25 \\
64.45\end{array}$ & $\begin{array}{l}1180 \\
1253 \\
4355\end{array}$ & $\begin{array}{l}17.41 \\
18.49 \\
64.1\end{array}$ & $\begin{array}{l}66 \\
66 \\
287\end{array}$ & $\begin{array}{l}15.75 \\
15.75 \\
68.5\end{array}$ & $\begin{array}{l}0.2 \\
0.2 \\
0.08\end{array}$ \\
\hline Economic status & $\begin{array}{l}\text { Low + sufficient } \\
\text { Good } \\
\text { Very good }\end{array}$ & $\begin{array}{l}1165 \\
4930 \\
1112\end{array}$ & $\begin{array}{l}16.16 \\
68.40 \\
15.44\end{array}$ & $\begin{array}{l}1128 \\
4624 \\
1036\end{array}$ & $\begin{array}{l}15.65 \\
68.22 \\
83.87\end{array}$ & $\begin{array}{l}37 \\
306 \\
76\end{array}$ & $\begin{array}{l}8.83 \\
73.03 \\
18.14\end{array}$ & $\begin{array}{l}<0.001 \\
0.04 \\
0.1\end{array}$ \\
\hline Marital status & $\begin{array}{l}\text { Single } \\
\text { In a relationship } \\
\text { Married }\end{array}$ & $\begin{array}{l}44 \\
1578 \\
5591\end{array}$ & $\begin{array}{l}0.61 \\
21.89 \\
77.57\end{array}$ & $\begin{array}{l}38 \\
1497 \\
5253\end{array}$ & $\begin{array}{l}5.02 \\
22.09 \\
72.89\end{array}$ & $\begin{array}{l}0 \\
81 \\
338\end{array}$ & $\begin{array}{l}0 \\
19.33 \\
80.67\end{array}$ & $\begin{array}{l}0.2 \\
0.2 \\
0.3\end{array}$ \\
\hline \multicolumn{2}{|l|}{ Stress level (points)* } & 4.62 & 0.82 & 4.67 & 1.93 & 3.89 & 1.89 & $<0.001$ \\
\hline \multicolumn{2}{|l|}{ Assessment of relationship (points)* } & 8.82 & 2.48 & 8.80 & 1.57 & 9.30 & 1.11 & $<0.001$ \\
\hline \multicolumn{2}{|l|}{ Depression } & 251 & 3.5 & 245 & 3.6 & 6 & 1.4 & 0.01 \\
\hline \multicolumn{2}{|l|}{ Anxiety disorders } & 190 & 2.6 & 186 & 2.7 & 4 & 0.9 & 0.03 \\
\hline \multirow[t]{7}{*}{ Pregnancy ailments } & Nausea & 779 & 10.8 & 15 & 3.58 & 764 & 11.26 & $<0.001$ \\
\hline & Vomiting & 244 & 3.4 & 3 & 0.70 & 241 & 35.50 & $<0.001$ \\
\hline & Backache & 2764 & 38.4 & 95 & 22.67 & 2669 & 39.32 & $<0.001$ \\
\hline & Frequent urination & 5234 & 72.6 & 247 & 58.95 & 4987 & 73.47 & $<0.001$ \\
\hline & Breathing problems & 1511 & 21 & 30 & 7.16 & 1481 & 21.82 & $<0.001$ \\
\hline & Leg cramps & 2167 & 30.1 & 75 & 17.90 & 2092 & 30.82 & $<0.001$ \\
\hline & Fetal movements & 1476 & 20.5 & 37 & 8.83 & 1439 & 21.20 & $<0.001$ \\
\hline
\end{tabular}

No number, inh. inhabitants, BMI body mass index

$*$ Mean $/ \pm \mathrm{SD}$ 
Table 2 Sleep patterns of women in each trimester of pregnancy

\begin{tabular}{|c|c|c|c|c|c|c|c|c|c|}
\hline & & \multicolumn{2}{|c|}{$\begin{array}{l}\text { I trimester } 791 \\
\text { Good } 39 \\
\text { Poor } 752\end{array}$} & \multicolumn{2}{|c|}{$\begin{array}{l}\text { II trimester } \\
2580 \\
\text { Good } 181 \\
\text { Poor } 2399\end{array}$} & \multirow[b]{2}{*}{$p$ I vs II tr } & \multicolumn{2}{|c|}{$\begin{array}{l}\text { III trimester } \\
3836 \\
\text { Good } 199 \\
\text { Poor } 3637\end{array}$} & \multirow[b]{2}{*}{$p$ II vs III tr } \\
\hline & & No & $\%$ & No & $\%$ & & No & $\%$ & \\
\hline Time needed to fall asleep & $\begin{array}{l}0<15 \mathrm{~min} \\
15-30 \mathrm{~min} \\
30-45 \mathrm{~min} \\
45-60 \mathrm{~min} \\
\text { Over } 1 \mathrm{~h}\end{array}$ & $\begin{array}{l}321 \\
270 \\
100 \\
79 \\
21\end{array}$ & $\begin{array}{l}40.58 \\
34.13 \\
12.64 \\
9.99 \\
2.66\end{array}$ & $\begin{array}{l}888 \\
965 \\
341 \\
310 \\
76\end{array}$ & $\begin{array}{l}34.42 \\
37.4 \\
13.22 \\
12.02 \\
2.94\end{array}$ & $\begin{array}{l}0.002 \\
0.1 \\
0.72 \\
0.13 \\
0.72\end{array}$ & $\begin{array}{l}872 \\
1895 \\
491 \\
421 \\
157\end{array}$ & $\begin{array}{l}22.73 \\
49.41 \\
12.8 \\
10.97 \\
4.09\end{array}$ & $\begin{array}{l}<0.001 \\
<0.001 \\
0.62 \\
0.2 \\
0.02\end{array}$ \\
\hline Difficulties in falling asleep within $30 \mathrm{~min}$ & $\begin{array}{l}\text { None } \\
\text { 1/week } \\
\text { 2-3/week } \\
>3 / \text { week }\end{array}$ & $\begin{array}{l}293 \\
198 \\
158 \\
142\end{array}$ & $\begin{array}{l}37.04 \\
25.03 \\
19.97 \\
17.96\end{array}$ & $\begin{array}{l}834 \\
643 \\
530 \\
573\end{array}$ & $\begin{array}{l}32.33 \\
24.92 \\
20.54 \\
22.21\end{array}$ & $\begin{array}{l}0.02 \\
0.96 \\
0.76 \\
0.01\end{array}$ & $\begin{array}{l}807 \\
1112 \\
1035 \\
882\end{array}$ & $\begin{array}{l}21.03 \\
28.99 \\
26.98 \\
23\end{array}$ & $\begin{array}{l}<0.001 \\
<0.001 \\
0.001 \\
0.86\end{array}$ \\
\hline Night sleep duration & $\begin{array}{l}<4 \mathrm{~h} \\
4-6 \mathrm{~h} \\
7-8 \mathrm{~h} \\
>8 \mathrm{~h}\end{array}$ & $\begin{array}{l}17 \\
245 \\
379 \\
150\end{array}$ & $\begin{array}{l}2.16 \\
30.97 \\
47.91 \\
18.96\end{array}$ & $\begin{array}{l}53 \\
839 \\
1204 \\
484\end{array}$ & $\begin{array}{l}2.05 \\
32.52 \\
46.67 \\
18.76\end{array}$ & $\begin{array}{l}0.89 \\
0.43 \\
0.54 \\
0.92\end{array}$ & $\begin{array}{l}90 \\
1231 \\
1825 \\
690\end{array}$ & $\begin{array}{l}2.34 \\
32.09 \\
47.58 \\
17.99\end{array}$ & $\begin{array}{l}0.49 \\
0.55 \\
0.54 \\
0.82\end{array}$ \\
\hline Waking up during the night & $\begin{array}{l}\text { No } \\
\text { 1/week } \\
\text { 2-3/week } \\
>3 / \text { week }\end{array}$ & $\begin{array}{l}77 \\
76 \\
212 \\
426\end{array}$ & $\begin{array}{l}9.74 \\
9.6 \\
26.8 \\
53.86\end{array}$ & $\begin{array}{l}208 \\
304 \\
623 \\
1445\end{array}$ & $\begin{array}{l}8.06 \\
11.78 \\
24.15 \\
67.01\end{array}$ & $\begin{array}{l}0.14 \\
0.14 \\
0.13 \\
0.29\end{array}$ & $\begin{array}{l}164 \\
232 \\
590 \\
2850\end{array}$ & $\begin{array}{l}4.28 \\
6.05 \\
15.38 \\
74.29\end{array}$ & $\begin{array}{l}<0.001 \\
<0.001 \\
<0.001 \\
0.002\end{array}$ \\
\hline Use of hypnotics & & 18 & 2.28 & 55 & 2.13 & 0.78 & 55 & 1.43 & 0.06 \\
\hline Use of hypnotics & $\begin{array}{l}\text { No } \\
\text { 1/week } \\
\text { 2-3/week } \\
>3 / \text { week }\end{array}$ & $\begin{array}{l}773 \\
10 \\
3 \\
5\end{array}$ & $\begin{array}{l}97.72 \\
1.26 \\
0.39 \\
0.63\end{array}$ & $\begin{array}{l}2525 \\
31 \\
15 \\
9\end{array}$ & $\begin{array}{l}97.87 \\
1.2 \\
0.58 \\
0.35\end{array}$ & $\begin{array}{l}0.53 \\
0.85 \\
0.27 \\
0.53\end{array}$ & $\begin{array}{l}3774 \\
31 \\
19 \\
12\end{array}$ & $\begin{array}{l}98.38 \\
0.81 \\
0.5 \\
0.31\end{array}$ & $\begin{array}{l}0.8 \\
0.08 \\
0.45 \\
0.8\end{array}$ \\
\hline Day time sleepiness & & 683 & 86.35 & 2217 & 85.93 & 0.82 & 2984 & 77.79 & $<0.001$ \\
\hline Day time naps & & 669 & 84.58 & 1944 & 75.35 & $<0.001$ & 2774 & 72.31 & 0.8 \\
\hline Nap duration & $\begin{array}{l}\text { None } \\
1 \mathrm{~h} \\
2-3 \mathrm{~h} \\
>3 \mathrm{~h}\end{array}$ & $\begin{array}{l}122 \\
405 \\
246 \\
18\end{array}$ & $\begin{array}{l}15.42 \\
51.2 \\
31.1 \\
2.28\end{array}$ & $\begin{array}{l}636 \\
1342 \\
562 \\
40\end{array}$ & $\begin{array}{l}24.65 \\
52.02 \\
21.78 \\
1.55\end{array}$ & $\begin{array}{l}<0.001 \\
0.7 \\
<0.001 \\
0.21\end{array}$ & $\begin{array}{l}1062 \\
2034 \\
711 \\
29\end{array}$ & $\begin{array}{l}27.69 \\
53.02 \\
18.53 \\
0.76\end{array}$ & $\begin{array}{l}0.007 \\
0.43 \\
0.002 \\
0.09\end{array}$ \\
\hline Lack of alertness during the day & $\begin{array}{l}\text { None } \\
\text { 1/week } \\
\text { 2-3/week } \\
>3 / \text { week }\end{array}$ & $\begin{array}{l}296 \\
209 \\
189 \\
97\end{array}$ & $\begin{array}{l}37.42 \\
26.42 \\
23.89 \\
12.27\end{array}$ & $\begin{array}{l}1206 \\
715 \\
499 \\
160\end{array}$ & $\begin{array}{l}46.74 \\
27.71 \\
19.34 \\
6.21\end{array}$ & $\begin{array}{l}<0.001 \\
0.5 \\
0.006 \\
<0.001\end{array}$ & $\begin{array}{l}1263 \\
1788 \\
597 \\
188\end{array}$ & $\begin{array}{l}32.93 \\
46.61 \\
15.56 \\
4.9\end{array}$ & $\begin{array}{l}<0.001 \\
<0.001 \\
<0.001 \\
0.08\end{array}$ \\
\hline
\end{tabular}

No number, $t r$. trimester, $\min$ minutes, $h$ hours

Specific data are presented in Table 2. A total of $95.1 \%$ of the respondents in the first trimester, $93 \%$ in the second trimester and $94.8 \%$ in the third trimester had poor sleep quality according to the PSQI. Almost all women with good sleep quality did not share a bed with any other person ( 97.6 vs. $93.9 \%$ of persons sharing bed; $p=0.001$ ). $40.6 \%$ of respondents in the first trimester declared to fall asleep within $15 \mathrm{~min}$, while over $4 \%$ of women in the third trimester were not able to fall asleep within an hour. $1.76 \%$ of women admitted to using sleep medications during gestation.

The study group was further divided into two groups according to the PSQI. Only $5.81 \%$ of the respondents were qualified as having "good" sleep. The number of the respondents with "poor" sleep according to the PSQI was much higher compared to subjective opinions regarding the quality of sleep obtained from the respondents (data presented in the previous paper [26]). $77.1 \%$ of the respondents reported sleep problems, while $22.9 \%$ declared that they slept well $(p<0.01)$. In each trimester of pregnancy, significantly more women were found to have sleep problems according to objective sleep quality assessment compared to their subjective opinion (PSQI poor sleep: $79.6 \%$ in the first, $92.9 \%$ in the second and $94.7 \%$ in the third trimester vs. subjective poor sleep: $71.8 \%$ in the first trimester, $73.6 \%$ in the second trimester and $80.6 \%$ in the third trimester; $p<0.01$ ).

The characteristics of the respondents with poor and good sleep quality according to the PSQI are presented in Table 1. Significantly more women with poor sleep quality assessed their socioeconomic status as bad or sufficient (15.7 vs $8.8 \% ; p<0.001$ ), stress level as higher (mean 4.7 points vs 3.9 points; $p<0.001$ ), had lower relationship rating (mean 8.8 points vs 9.3 points; $p<0.001$ ) or suffered 
from depression and anxiety disorders. A significantly larger number of women with poor sleep reported taking daytime naps compared to women with good sleep quality (73 vs. $63 \% ; p<0.001)$.

Logistic regression analysis was performed to identify the factors which influenced the risk of poor sleep during gestation. Detailed results are presented in Table 3. Pregnancy ailments were the strongest independent risk factors of poor sleep quality during gestation.

\section{Discussion}

Our study demonstrated that pregnancy is a period in women's life when they experience specific sleep disorders and suffer from poor sleep quality. Interestingly, women declared their sleep quality during pregnancy to be better than it was assessed with the PSQI [26]. Data published worldwide are conflicting. Results similar to those presented in our paper were reported in a study of over 11,000 pregnant women by Sedov et al. [12]. According to the authors, $95 \%$ of women experienced poor sleep quality. Christian et al. investigated objective sleep quality in 133 women using the PSQI during each trimester of pregnancy and at 4-11 weeks postpartum [27]. In their study, $71 \%$ of pregnant women reported poor sleep quality. In a group of 400 Taiwanese pregnant women, the prevalence of pregnancy-associated sleep disturbance according to the PSQI was $65.5 \%$ [28]. Trend analyses of PSQI score indicated a linear gradual decline in sleep quality as the pregnancy progressed. In another Taiwanese study including 300 pregnant and non-pregnant women, the prevalence of poor sleep quality was $60 \%$ for second- and third-trimester

Table 3 Logistic regression analysis of factors influencing the occurrence of poor sleep quality

\begin{tabular}{lll}
\hline & aOR & $95 \%$ CI \\
\hline Low or sufficient economic status & 1.13 & $1.01-1.32$ \\
Stress level & 1.09 & $1.04-1.15$ \\
Assessment of relationship & 0.91 & $0.89-0.96$ \\
Nausea & 2.15 & $1.77-2.73^{*}$ \\
Backpain & 2.1 & $1.99-2.29^{*}$ \\
Nocturnal urination & 2.42 & $2.11-2.73^{*}$ \\
Breathing difficulties in the supine position & 2.5 & $2.11-2.98^{*}$ \\
Leg cramps & 1.45 & $1.27-1.77^{*}$ \\
Fetal movements & 2.66 & $2.21-3.21^{*}$ \\
\hline
\end{tabular}

$a O R$ adjusted odds ratio, $95 \%$ CI 95\% confidence interval ${ }^{*} p<0.001$

Variables adjusted in the analysis: age, parity, economic status, employment, stress level, marital status, assessment of relationship, pregnancy ailments pregnant women and $48 \%$ for non-pregnant women [5]. Conversely, other publications showed significantly lower rates of sleep disturbances in a population of pregnant women. Gelaya et al. classified only $17 \%$ of the respondents as having poor sleep quality in a group of 1298 pregnant women between 24 and 28 gestational weeks [29]. Differences in the rates of women suffering from sleep disorders may be related to a different population in which the studies were conducted.

In our study, significantly fewer women assessed their sleep quality as poor compared to PSQI findings. Differences in the subjective and objective opinions on sleep quality may also be noticed in other studies. A cross-sectional survey of 2345 pregnant women in China showed $15.2 \%$ of pregnant women who reported having sleep problems [3]. Another study conducted in 454 pregnant Chinese women demonstrated that $87 \%$ of them experienced poor sleep quality (PSQI score $>5$ ). Poorer overall sleep quality, subjective sleep quality, lower sleep efficiency and sleep disturbances were the most prevalent during the third trimester [30]. Cai et al. performed a survey in 1993 pregnant women and 598 non-pregnant women in China. The overall prevalence of sleep disorder-related symptoms in pregnant women was significantly higher than in the non-pregnant ones (56.1 vs. $29.9 \%, p<0.05)$. Nocturnal sleep time $(8.0 \pm 1.3 \mathrm{~h})$ was shorter in the third trimester compared to non-pregnant women $(8.2 \pm 1.1 \mathrm{~h} ; p<0.05)$ [31].

In our study, the highest percentages of respondents with sleep disorders were identified in the first and the third trimesters of pregnancy. Our results are similar to those presented by others. In Nigerian pregnant women, the prevalence of sleep disorders was only $35.5 \%$. More women experienced sleep disturbances in the first (42.1\%) and third (40\%) trimesters of pregnancy compared to the second one (25.3\%).[32]. Skoczylas et al. conducted a study evaluating sleep disorders in a group of 147 pregnant Polish women and found the highest frequency of sleep disturbances in the first and third trimesters of pregnancy ( 84.3 and $92.3 \%$, respectively) [33]. Analogous results were presented in other studies. Naud et al. reported the deterioration of sleep quality an overall PSQI scores from the second to the third trimesters of pregnancy $(5.26 \pm 3.16$ vs. $6.73 \pm 4.02 ; p<0.01) .36 \%$ of women in the second and $56 \%$ of women in the third trimester were classified as having poor sleep quality [3]. Hutchison et al. reported that only $29 \%$ of pregnant women in the third trimester described their sleep as good; while before pregnancy, $82 \%$ of the respondents declared to have "good" sleep [7]. Hashmi et al. reported that the majority of women experienced sleep problems in the third trimester with over $98 \%$ reporting nocturnal awakenings. The researchers found increased wake time after sleep onset and reduced nighttime sleep duration in the third trimester compared to the first two trimesters of pregnancy [34]. 
In our study, the economic status was found to pay a significant role in the occurrence of poor sleep quality in pregnant women. Significantly more women declaring low or sufficient economic status were characterized by poor sleep. $\mathrm{Xu}$ et al. also found low income level to be related to insufficient sleep duration [3]. Unemployment increased the risk of sleep disorders $(\mathrm{OR}=1.46 ; 95 \%$ CI 1.13-1.88), while living in rural areas decreased the risk of poor sleep $(\mathrm{OR}=0.64$; 95\% CI 0.50-0.83). Pregnant women exposed to secondhand smoke were more likely to have sleep problems compared to those without exposure to secondhand smoke $(\mathrm{OR}=1.43$; 95\% CI 1.10-1.86) [3]. Naud et al. reported annual family income below $\$ 40,000$ and single motherhood to be associated with poor sleep in the second and third trimesters of pregnancy [2]. Stress or anxiety were also found to be related to sleep disorders in pregnant women. Poor sleepers (PSQI global score $>5$ ) had the increased odds of experiencing depression ( $\mathrm{OR}=6.47$; 95\% CI 4.56-9.18), anxiety $(\mathrm{OR}=3.59 ; 95 \% \mathrm{CI} 2.45-5.26)$, and stress $(\mathrm{OR}=4.37 ; 95 \%$ CI 2.88-6.65) [24]. Analogously, in our study, poor sleep respondents reported a higher overall stress level and more frequent depression and anxiety disorders.

Pregnant women experience numerous disturbances influencing sleep quality. The majority of studies point at several pregnancy ailments to be related to poor sleep quality. Mindell et al. found nighttime awakening (100\%), frequent urination $(83 \%)$, uncomfortable position $(79 \%)$ to be most frequently related to sleep problems [8]. Similarly, according to a survey of 147 pregnant women by Skoczylas et al., the most common causes of low PSQI score were: uncomfortable body position (68\%), nighttime urination (55\%), and pregnancy-related stress (42\%) [33]. In another Polish study of 266 pregnant women in the third trimester of pregnancy, $84.2 \%$ reported various sleep problems including: nighttime awakenings ( $n=157 ; 59.0 \%)$, non-restorative sleep $(n=66$; $24.8 \%)$, prob-lem with falling asleep $(n=62 ; 23.3 \%)$, early morning awakenings $(n=55 ; 20.7 \%)$, snoring $(n=80$; $30.1 \%)$, tingling in the legs $(n=70 ; 26.3 \%)$, and eating at night $(n=61 ; 22.9 \%)$ [35].

Previous studies confirmed a relationship between the occurrence of sleep disorders and depression, wherein depressed pregnant women were more likely to suffer from sleep problems during pregnancy [4, 5]. Poor sleep quality may be a trigger of depression during pregnancy $[5,6$, 36]. In our study, women with poor sleep quality declared that they suffered from depression and anxiety disorders significantly more often. In a study by Ko et al. conducted in a group of 300 women, a high prevalence of antenatal depression was found in pregnant women in the second and third trimesters (27.3-36.0\%). Stress affected sleep quality in pregnant women [5]. Tsai et al. found the risk of clinically meaningful depressive symptoms to be significantly increased in women with objective total nighttime sleep shorter than $6 \mathrm{~h}(\mathrm{OR}=2.53,95 \% \mathrm{CI} 1.26-5.08)$ and selfreported poor sleep quality $(\mathrm{OR}=3.31,95 \% \mathrm{CI} 1.74-6.30)$ [36]. Yu et al. conducted a cross-sectional study to evaluate the longitudinal association of sleep with depression and anxiety in Chinese pregnant women recruited in Zhoushan Maternal and Child Care Hospital [4]. The prevalence of depression was $35.64,24.23$, and $26.24 \%$, and of anxiety was $22.57,17.41$, and $21.04 \%$ in the first, second and third trimesters of pregnancy, respectively. Women who slept less than $8 \mathrm{~h}$ per day were at a higher risk of depression $(\mathrm{OR}=1.75,95 \% \mathrm{CI} 1.39-2.20$ in the first, $\mathrm{OR}=1.52,95 \%$ CI $1.26-2.05$ in the second, OR $=1.60,95 \%$ CI $1.18-2.05$ in the third trimester) and anxiety $(\mathrm{OR}=2.00,95 \% \mathrm{CI}$ $1.57-2.55$ in the first, $\mathrm{OR}=1.86,95 \%$ CI $1.37-2.54$ in the second, $\mathrm{OR}=1.33,95 \% \mathrm{CI} 0.99-1.79$ in the third trimester). A multilevel model used in a longitudinal analysis revealed that women with subjective "fair" or "bad" sleep quality were at an increased risk of depression $(\mathrm{OR}=1.54-3.71)$ and anxiety $(\mathrm{OR}=2.38-7.53)$ during pregnancy [4].

A uniquely large cohort of pregnant women is the strength of our study. To the best of our knowledge, no research has been published in such a large cohort so far. The PSQI is an objective tool for sleep quality assessment. Obviously, a questionnaire is not an ideal tool for the diagnosis of any sleep disorders. Conversely, choosing such an objective and validated diagnosing tool as polysomnography would result in a significant reduction in the size of the study group. The anonymity and distribution of the questionnaire via the internet might have promoted the honesty of the answers. However, there are some limitations of the study. It was distributed online, so the question of the reliability of the results is a valid concern. However, despite the obvious limitation, it was possible to reach a large group of pregnant women throughout the country. Although the study was conducted in Poland and included Polish-speaking pregnant women, we assume that pregnant women in Poland are similar to other pregnant women in Europe and the study results could apply to the entire population of pregnant women in developed countries.

\section{Conclusions}

In conclusion, sleep disorders are common among pregnant women in Poland and increase significantly as the pregnancy progresses. The assessment of risk factors during pregnancy could be helpful to evaluate the risk of sleep problems. Developing and introducing a simple and easily available screening tool to assess sleep quality in clinical practice might improve the quality of the health care of pregnant women. However, sleep hygiene could be discussed prior to pregnancy. Further research on modified risk factors of poor 
sleep during pregnancy and the impact of modifying these factors on sleep quality are required in the future.

\section{Declarations}

Conflict of interest The authors declare that they have no conflict of interest.

Ethical approval The study was conducted according to the guidelines of the Declaration of Helsinki, and approved by the Ethics Committee of Medical University of Warsaw (protocol code 124/2018).

Open Access This article is licensed under a Creative Commons Attribution 4.0 International License, which permits use, sharing, adaptation, distribution and reproduction in any medium or format, as long as you give appropriate credit to the original author(s) and the source, provide a link to the Creative Commons licence, and indicate if changes were made. The images or other third party material in this article are included in the article's Creative Commons licence, unless indicated otherwise in a credit line to the material. If material is not included in the article's Creative Commons licence and your intended use is not permitted by statutory regulation or exceeds the permitted use, you will need to obtain permission directly from the copyright holder. To view a copy of this licence, visit http://creativecommons.org/licenses/by/4.0/.

\section{References}

1. Irwin MR. Why sleep is important for health: a psychoneuroimmunology perspective. Annu Rev Psychol. 2015;3(66):143-72.

2. Naud K, Ouellet A, Brown C, et al. Is sleep disturbed in pregnancy? ObstetGynecol Can. 2010;32(1):28-34.

3. Xu X, Liu D, Zhang Z, Sharma M, Zhao Y. Sleep duration and quality in pregnant women: a cross-sectional survey in China. Int $\mathrm{J}$ Environ Res Public Health. 2017;14(7):817.

4. Yu Y, Li M, Pu L, et al. Sleep was associated with depression and anxiety status during pregnancy: a prospective longitudinal study. Arch WomensMent Health. 2017;20(5):695-701.

5. Ko SH, Chang SC, Chen $\mathrm{CH}$. A comparative study of sleep quality between pregnant and nonpregnant Taiwanese women. J NursScholarsh. 2010;42(1):23-30.

6. Skouteris H, Wertheim EH, Germano C, et al. Assessing sleep during pregnancy: a study across two time points examining the Pittsburgh Sleep Quality Index and associations with depressive symptoms. Womens Health Issues. 2009;19(1):45-51.

7. Hutchison BL, Stone PR, et al. A postal survey of maternal sleep in late pregnancy. BMC Pregnancy Childbirth. 2012;12:144.

8. Mindell J, Cook R, Nikolovski J. Sleep patterns and sleep disturbances across pregnancy. Sleep Med. 2015;16(4):483-8.

9. Okun M, Coussons-Read M. Sleep disruption during pregnancy: how does it influence serum cytokines? J ReprodImmunol. 2007;73(2):158-65.

10. Tomfohr L, Buliga E, Letourneau N, et al. Trajectories of sleep quality and associations with mood during the perinatal period. Sleep. 2015;38(8):1237-45.

11. Buysse D, Reynolds C, Monk T, et al. The Pittsburgh Sleep Quality Index: a new instrument for psychiatric practice and research. Psychiatry Res. 1989;28(2):193-213.

12. Sedov ID, Cameron EE, Madigan S, Tomfohr-Madsen LM. Sleep quality during pregnancy: a meta-analysis. Sleep Med Rev. 2018;38:168-76.
13. Smagula SF, Stone KL, Fabio A, Cauley JA. Risk factors for sleep disturbances in older adults: evidence from prospective studies. Sleep Med Rev. 2016;25:21-30.

14. Hajduk A. Subietywnajakośćsnu u chorychnatoczeńrumieniowatyu kładowy. GdańskiUniwersytetMedyczny: Gdańsk; 2015.

15. Doi Y, Minowa M, Uchiyama M, et al. Psychometric assessment of subjective sleep quality using the Japanese version of the Pittsburgh Sleep Quality Index (PSQI-J) in psychiatric disordered and control subjects. Psychiatry Res. 2000;97(2-3):165-72.

16. Carpentera JS, Andrykowskia MA. Psychometric evaluation of the Pittsburgh Sleep Quality Index. J Psychosom Res. 1998;45(1):5-13.

17. Backhaus J, Junghanns K, Broocks A, et al. Test-retest reliability and validity of the Pittsburgh Sleep Quality Index in primary insomnia. J Psychos Res. 2002;53(3):737-40.

18. Takács J, Bódizs R, Ujma PP, et al. Reliability and validity of the Hungarian version of the Pittsburgh Sleep Quality Index (PSQIHUN): comparing psychiatric patients with control subjects. Sleep Breath. 2016;20(3):1045-51.

19. Curcio G, Tempesta D, Scarlata S, et al. Validity of the Italian version of the Pittsburgh Sleep Quality Index (PSQI). NeurolSci. 2013;34(4):511-9.

20. Bertolazi AN, Fagondes SC, Hoff LS, et al. Validation of the Brazilian Portuguese version of the Pittsburgh Sleep Quality Index. Sleep Med. 2011;12(1):70-5.

21. Zhong QY, Gelaye B, Sánchez SE, Williams MA. Psychometric properties of the Pittsburgh Sleep Quality Index (PSQI) in a cohort of Peruvian pregnant women. J Clin Sleep Med. 2015;11(8):869-77.

22. Popević MB, Milovanović APS, Milovanović S, et al. Reliability and validity of the Pittsburgh Sleep Quality Index-Serbian translation. Eval Health Prof. 2014;41(1):67-81.

23. Moghaddam JF, Nakhaee N, Sheibani V, et al. Reliability and validity of the Persian version of the Pittsburgh Sleep Quality Index (PSQI-P). Sleep Breath. 2012;16(1):79-82.

24. Qiu C, Gelaye B, Zhong QY, et al. Construct validity and factor structure of the Pittsburgh Sleep Quality Index among pregnant women in a Pacific-Northwest cohort. Sleep Breath. 2016;20(1):293-301.

25. Staniszewska A, Mąka A, Religioni U, Olejniczak D. Sleep disturbances among patients with epilepsy. Neuropsychiatr Dis Treat. 2017;13:1797-803.

26. Smyka M, Kosińska-Kaczyńska K, Sochacki-Wójcicka N, Zgliczyńska M, Wielgoś M. Sleep problems in pregnancy-a crosssectional study in over 7000 pregnant women in Poland. Int J Environ Res Public Health. 2020;17:5306.

27. Christian LM, Carroll JE, Porter K, Hall MH. Sleep quality across pregnancy and postpartum: effects of parity and race. Sleep Med. 2014;15(12):1477-83.

28. Hung HM, Tsai PS, Ko SH, Chen CH. Patterns and predictors of sleep quality in Taiwanese pregnant women. MCN Am J Matern Child Nurs. 2013;38(2):95-101.

29. Gelaye B, Addae G, Neway B, et al. Poor sleep quality, antepartum depression and suicidal ideation among pregnant women. J Affect Disord. 2017;209:195-200.

30. Yang Y, Mao J, Ye Z, et al. Determinants of sleep quality among pregnant women in China: a cross-sectional survey. J MaternFetal Neonatal Med. 2018;31(22):2980-5.

31. Cai XH, Xie YP, Li XC, et al. The prevalence and associated risk factors of sleep disorder-related symptoms in pregnant women in China. Sleep Breathing. 2013;17:951-6.

32. Osaikhuwuomwan JA, Aina OI, Aziken ME. Sleep disorders in women attending antenatal care at a tertiary hospital in Nigeria. Niger Postgrad Med J. 2014;21(2):155-9.

33. Skoczylas M, Krawczyk A, Łęgowik P, Kalinka J. Sleep disorders among pregnant women. Gin Pol Med Project. 2014;4:34. 
34. Hashmi AM, Bhatia SK, Bhatia SK, Khawaja IS. Insomnia during pregnancy: diagnosis and rational interventions. Pak J Med Sci. 2016;32(4):1030-7.

35. Wołyńczyk-Gmaj D, Różańska-Walędziak A, Ziemka S, et al. Insomnia in pregnancy is associated with depressive symptoms and eating at night. J Clin Sleep Med. 2017;13(10):1171-6.

36. Tsai SY, Lin JW, Wu WW, et al. Sleep disturbances and symptoms of depression and daytime sleepiness in pregnant women. Birth. 2016;43(2):176-83.
Publisher's Note Springer Nature remains neutral with regard to jurisdictional claims in published maps and institutional affiliations. 